\title{
OCCLUSAL SPLINTS VERSUS ULTRASOUND THERAPY IN MANAGEMENT OF ANTERIOR DISC DISPLACEMENT WITH REDUCTION. A RANDOMIZED CLINICAL TRIAL
}

\author{
Nourhan Ahmed Ragheb* and Wafaa Ibrahim Ibrahim**
}

\begin{abstract}
Purpose: To compare the effect of Stabilization Splint (SS), Anterior repositioning splint (ARS), and Ultrasound (US) therapy in improving pain, limited mouth opening and clicking in patients with Anterior Disc Displacement with Reduction (ADDwR).

Materials and Methods: 30 subjects were enrolled in this randomized clinical trial. Participants were randomly allocated into one of the three study groups of 10 patients each; Group I received a SS, Group II received ARS and Group III were treated with US. All the patients were recalled at baseline (before treatment), $1 \mathrm{~m}, 3 \mathrm{~m}$ and $6 \mathrm{~m}$ follow-up periods to evaluate pain, maximum mouth opening (MMO) and clicking. Pain level was evaluated using Visual Analogue Score (VAS). MMO was measured in mm. as the distance between maxillary and mandibular incisors. Detection of TMJ sounds was performed on opening or closing and was recorded.
\end{abstract}

Results: There was a significant decrease in the pain scores in the three groups with $\mathrm{P}<0.001$. There was a statistically significant improvement in MMO in SS and ARS P $<0.001$ while, in US group improvement was below the level of significance $P=0.269$. Improvement in clicking was present in SS group and ARS group. 9 patients in the US group still had clicking sound without statistical improvement in clicking throughout the follow-up period.

Conclusion: The use of occlusal splints in the management of painful ADDwR is a successful mode of treatment and helps in decreasing pain, improving MMO and clicking yet, is better to be used in combination with other treatment modalities.

* Lecturer, Prosthodontist, Department of Prosthodontics, Faculty of Oral and Dental Medicine, Kafr Elshiekh University, Kafr Eishiekh, Egypt.

** Lecturer, Prosthodontist, Department of Prosthodontics, Faculty of Oral and Dental Medicine, Delta University for Science and Technology, Mansoura, Egypt. 


\section{INTRODUCTION}

Temporomandibular disorders (TMD) are considered a real challenge in everyday practice due to the high complication of different phases such as diagnostic methods or treatment choices. ${ }^{1}$ TMD represent a group of musculoskeletal and neuromuscular conditions, affecting the temporomandibular joints, the masticatory muscles, and the surrounding tissues. ${ }^{2}$ They occur as a result of the physiological relationship between the articular disc and the condyle head variations. Regarding the Research Diagnostic Criteria for Temporomandibular Disorders (RDC/TMD), they can be divided into four basic types of articular disc displacements: DDwR, DDwR with intermittent locking, disc displacement without reduction (DDWoR) with limited opening. ${ }^{3}$

Moreover, the DDwR conditions represented $41 \%$ of the diagnoses of TMD that is frequently found. ${ }^{4}$ Observation of the condition of the DDwR under magnetic resonance imaging (MRI) show articular disc position located more anteriorly than normal in maximum intercuspation. ${ }^{5}$

The DC/TMD defines DDwR as an intracapsular biomechanical disorder when, in closed mouth position, the disc is in an anterior position relative to the condylar head, and the disc reduces upon opening of the mouth (medial and lateral displacement of the disc may also be present; clicking, popping, or snapping noises may occur with disc reduction. ${ }^{3}$ Clicking occurs when the condylar head of the mandible pass over the rear edge of the displaced articular disc during mouth opening and/or closing. After that, the disc does not return to the exact position in relation to the condyle when the mandible is again, upon closure, in the central position. Clicking may happen in the initial, middle, and final part of the mandible opening movement. ${ }^{6}$

In addition, the Pain is considered to be the most common symptom encountered among patients diagnosed with TMD ${ }^{2}$, other symptoms, including joint jumps, joint noises, reduced mouth opening (closed lock), difficulties in closing the mouth (subluxation or open lock) may frequently be encountered as well. ${ }^{7}$

Management of TMD cases can be either conservative or surgical treatment. ${ }^{8}$ Furthermore, the conservative treatments include analgesia, medications, physical therapy, occlusal adjustment, splint therapy, localized steam application, and external muscle. $^{?}$

Nonsurgical therapy should be the first treatment option to decrease the risk of postoperative surgical complications even though the surgical interferences may be successful. The splints may be classified into three major categories regarding their hypothesized function: relaxation/stabilization splints, distraction/pivot splints and repositioning splints. The latter have been described for the therapy of painful DDwR. ${ }^{9}$

Many conservative and reversible (non-surgical) treatment methods like self-care thermal packs (moist heat fomentation), jaw relaxation by diet of soft food, avoiding gum chewing and controlling the parafunctional habits, jaw exercises, ARS and physiotherapy like US therapy are considered to be the most common non-surgical treatment options recommended to treat TMD and DDwR. ${ }^{10,11,12}$

The SS is considered to be a clinical tool resource applied in dentistry for TMD treatment in addition to for the protection of dental structures and for the articular, muscular, and dental system. Besides, one of the offered mechanisms of action is the reduction in proprioception created by the disocclusion between the upper and lower teeth and the increased TMJ space. ${ }^{8}$ Moreover, the SS is known as the superior repositioning splint, Tanner appliance, Michigan splint, Fox appliance or the centric relation appliance. ${ }^{13}$

The ARS encourages a therapeutic mandibular position, forward to the maximum intercuspation 
position of the patient and influences the physiological- topographical relationship of the disc condyle complex. ${ }^{14,15}$ furthermore, the ARS seats a patient's mandible and TMJ into an anterior position. The ARS can be efficient for intermittent jaw locking with limited range of motion, particularly upon awakening, or for persistent TMJ arthralgia not responding to other therapy incorporating a stabilization splint. ${ }^{13}$ The ARS places the disc and mandible at the anterior region and guarantees a better disccondyle relationship, therefore allowing retrodiscal tissues to adapt. In addition, it allows regeneration of retrodiscal tissues and discrete ligaments and relieve pain by reducing the load on the joint. ${ }^{16}$

Even though, US therapy is usually employed in the management of TMD there is little published material reporting the comparative efficacy of different type of treatment currently available. ${ }^{12}$ Although, various studies have investigated the effectiveness of physical therapy and splint therapy in patients with DDwR,${ }^{17}$ there is a relative shortage of the effectiveness of these treatment modalities on Disk Displacement with reduction. In addition, Randomized Controlled Trials (RCT) have also failed to show a separate positive effect of splints. ${ }^{18}$

A number of previous studies have shown both, equal to ${ }^{19}$, or weaker ${ }^{20}$, outcomes in contrast with the other known treatment options employed in the management of TMDs. According to the knowledge of the authors, there were limited studies to date that compared the efficacy of SS, ARS, and US therapy in treatment of DDwR.

The aim of this study was therefore to compare and evaluate the effect of SS, ARS, and US therapy in controlling and improving pain, limited mouth opening and clicking in patients with DDwR. The null hypothesis is that there is no difference between SS, ARS, and US in improvement of pain, limited mouth opening and clicking in patients with DDwR.

\section{MATERIALS AND METHODS}

\section{Trial Design and Participant Selection}

This is a parallel randomized controlled clinical trial consisting of 30 subjects suffering from ADDwR Group IIa according to the RDC/TMD and confirmed by radiographic and clinical examination by one experienced well-trained examiner. ${ }^{21}$ Only the accessor could be blinded due to the nature of the interventions. Subjects were recruited from the outpatient clinic of Oral and Maxillofacial Surgery Department Faculty of Dentistry, Kafrelshiekh University.

Patients fulfilling the following inclusion criteria were included 1) Adults above 18 years including both genders; 2) completely dentulous patients or a single tooth is missing; 3 ) clicking sound present in the TMJ unilaterally or bilaterally during opening or closing; 4) presence of pain unilaterally or bilaterally in the area of TMJ. Exclusion criteria include 1) any systemic disease affecting the TMJ;2) psychological disorders; 3) previous surgery or trauma in the area of TMJ. Ethical approval for the study was obtained from the Ethical Committee of Faculty of Dentistry Kafrelshiekh University. After explanation of all the treatment steps, an informed consent was signed by all patients participating in the study.

Participants were randomly allocated into one of the three study groups of 10 patients each; Group I received a SS, Group II received ARS and Group III were treated with US. Participants were asked to pick-up their number from opaque, sealed and sequentially numbered envelopes which included computer generated random number (RANDOM. ORG) to detect the group he/she belonged.

\section{Sequence of treatment}

For Group I a SS was fabricated as follows. A maxillary and mandibular impressions were made using alginate impression material (Cavex Alginate, Holland BV) and poured in type IV dental stone (elite ${ }^{\circledR}$ stone, Zhermack GmbH Deutschland). 
Maxillary cast was mounted on a semi adjustable articulator (Bio-Art A7 Plus Articulator, Italy) using a maxillary facebow, and the mandibular cast was mounted using a centric record.

The stabilization splint was fabricated on the maxillary arch using dental vacuum sheet (Lucky Dental, China) and provided equal contact with all the mandibular teeth. fig: (1) The splint was inserted in the patient's mouth and necessary occlusal adjustments were performed. Indentation of the incisal edges and cusp tips were placed on the occlusal surface of the splint to which the opposing dentition are fitted.

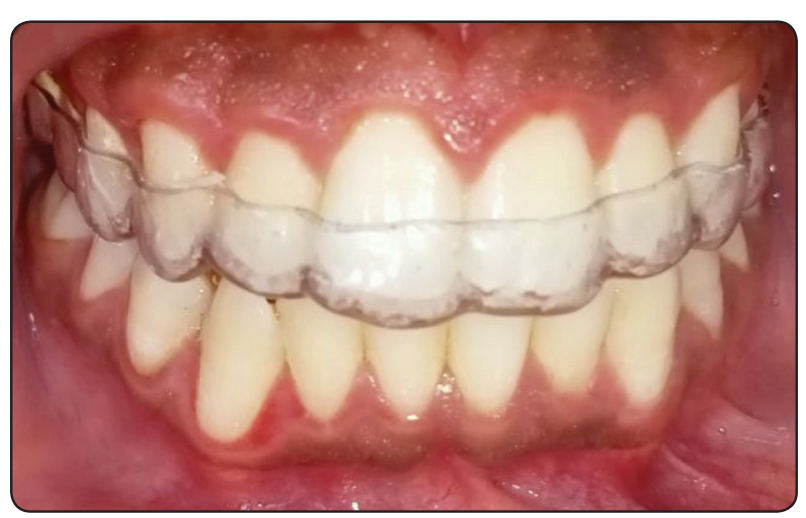

Fig. (1) Stabilization splint

For ARS the same steps of the fabrication of the SS were performed with an anterior bite position of the splint using hard clear cold cured acrylic resin (Acrostone, Egypt). The mandible was protruded the amount necessary to eliminate the clicking sound while opening and closing. The incisal pin of the articulator was adjusted to provide a space of $3 \mathrm{~mm}$ between posterior teeth. The anterior position of the bite was indexed into the ARS while fabricating it. A clasp was adapted on the maxillary first molar to retain the stent fig: $(\mathbf{2 , 3})$. Participants were instructed to wear the splints at nighttime during the follow-up period.

For Group III a pulsed US ( EMS Physio, Uk) was used with a frequency of $1 \mathrm{MHz}$ and 1 watt/ centimeter. The time of application was 2 minutes per region two times a week for one month and then discontinued for the remaining follow-up periods.
Applications were at three regions, the body of the masseter muscle, anterior temporal muscle fibers and TMJ. fig:(4)

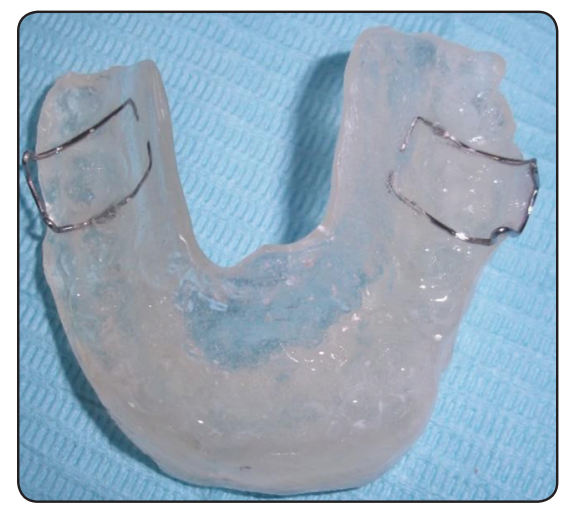

Fig. (2) Anterior repositing splint (extra oral)

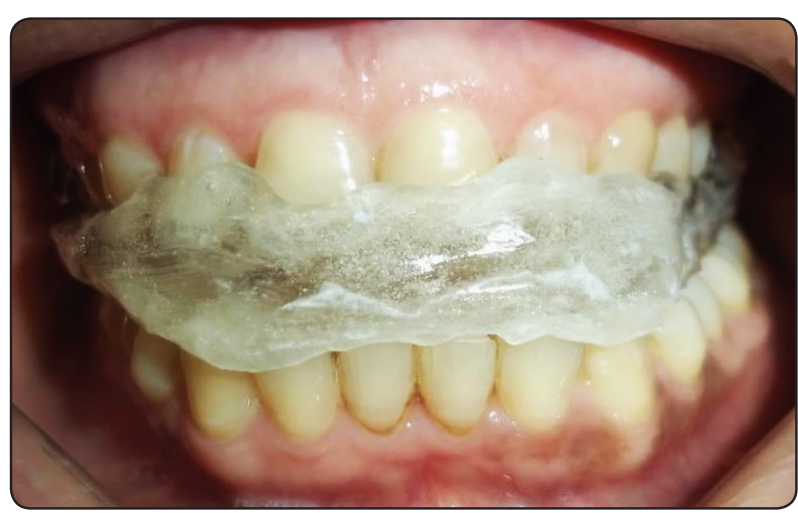

Fig. (3) Anterior repositing splint (intra oral)

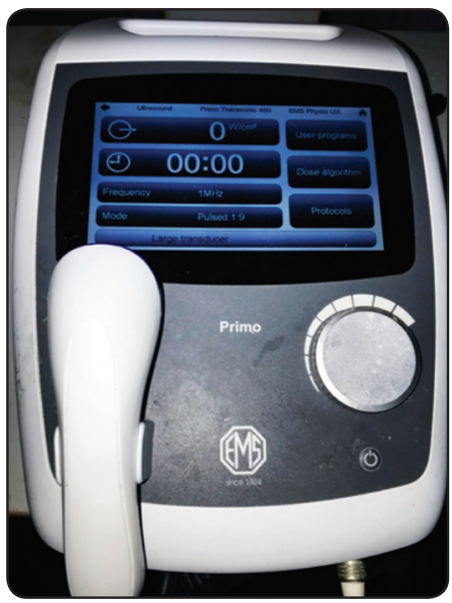

Fig. (4) Ultrasonic device

All the patients were recalled at baseline (before treatment), $1 \mathrm{~m}, 3 \mathrm{~m}$ and $6 \mathrm{~m}$ follow-up periods. Any 
necessary adjustments for the splints in group I and II was performed when needed or at the follow-up periods.

\section{Outcome measures}

\section{1- Pain}

Pain level was evaluated on palpation using VAS having scores from 0 to 10 . Choosing 0 represents no pain and 10 represents maximum pain.

\section{2- Maximum mouth opening}

The patients were instructed to open their mouth to the maximum position. The distance between maxillary and mandibular incisors was measured in $\mathrm{mm}$ using a caliper at the midline.

\section{3- Clicking}

According to the RDC/TMD examination, detection of TMJ sounds was performed bilaterally. Fingers were positioned over the TMJ anterior to tragus of the ear. The participants were instructed to open their mouth slowly 3 times to the maximum and then slowly closes to maximum intercuspation. Any sound detected on opening or closing was recorded.

\section{Statistical Analysis}

Data were statistically described in terms of mean \pm standard deviation $( \pm \mathrm{SD})$, or frequencies (number of cases) and percentages when appropriate. Numerical data were tested for the normal assumption using Shapiro Wilk test. Comparison of numerical variables between the study groups was done using one way analysis of variance (ANOVA) test with post hoc multiple 2-group comparisons. Within group comparison of numerical variables was done using repeated measures analysis of variance (ANOVA) test. For comparing categorical data between the study groups, Chi-square $\left(\mathrm{c}^{2}\right)$ test was performed. Exact test was used instead when the expected frequency is less than 5. Over time comparison within each group was done using McNemar test. Bonferroni adjustment was used to adjust for multiple comparisons. Two-sided $p$ values less than 0.05 was considered statistically significant. All statistical calculations were done using computer program IBM SPSS (Statistical Package for the Social Science; IBM Corp, Armonk, NY, USA) release 22 for Microsoft Windows.

\section{RESULTS}

The study sample consists of 30 participants, 19 males and 11 females with mean age of $30 \pm 3.9$. Thorough explanation of patients' enrollment, allocation, follow-up and analysis is shown in the consort flow chart of the study Fig(5). All the participants completed the follow-up period without dropouts.

\section{Pain Score}

As shown in Table 1 and fig :(6) there was no significant difference in the pain scores between the study groups at all the follow-up periods with $\mathrm{P}=(0.951,0.360,0.344,0.499)$ at baseline, $1 \mathrm{~m}$, $3 \mathrm{~m}$ and $6 \mathrm{~m}$ respectively. Additionally, it can be observed that there was a significant decrease in the pain scores throughout all the follow-up periods in the three groups with $\mathrm{P}<0.001$. A non-significant difference was detected when every two groups were compared separately.

\section{Maximum Mouth Opening}

Table 2 and fig:(7) show that there was no statistically significant difference between the study groups at the baseline $\mathrm{P}=0.566$ while there was a statistically significant difference at 1,3 and $6 \mathrm{~m}$ $\mathrm{P}<0.001$. Throughout the follow-up period within each group, there was a significant improvement in MMO in the SS and ARS groups $\mathrm{P}<0.001$. There was an improvement in MMO in US group but it was below the level of significance $\mathrm{P}=0.269$. Comparing every two groups separately revealed a non-significant difference between SS and ARS with P-values of $(0.321,0.135,0.025,0.091)$ at baseline, $1 \mathrm{~m}, 3 \mathrm{~m}$ and $6 \mathrm{~m}$ follow-up periods. Nevertheless, a significant improvement in MMO was observed in SS and ARS when compared to US at 1, 3 and $6 \mathrm{~m}$ with $\mathrm{P}$-value $<0.001$. 


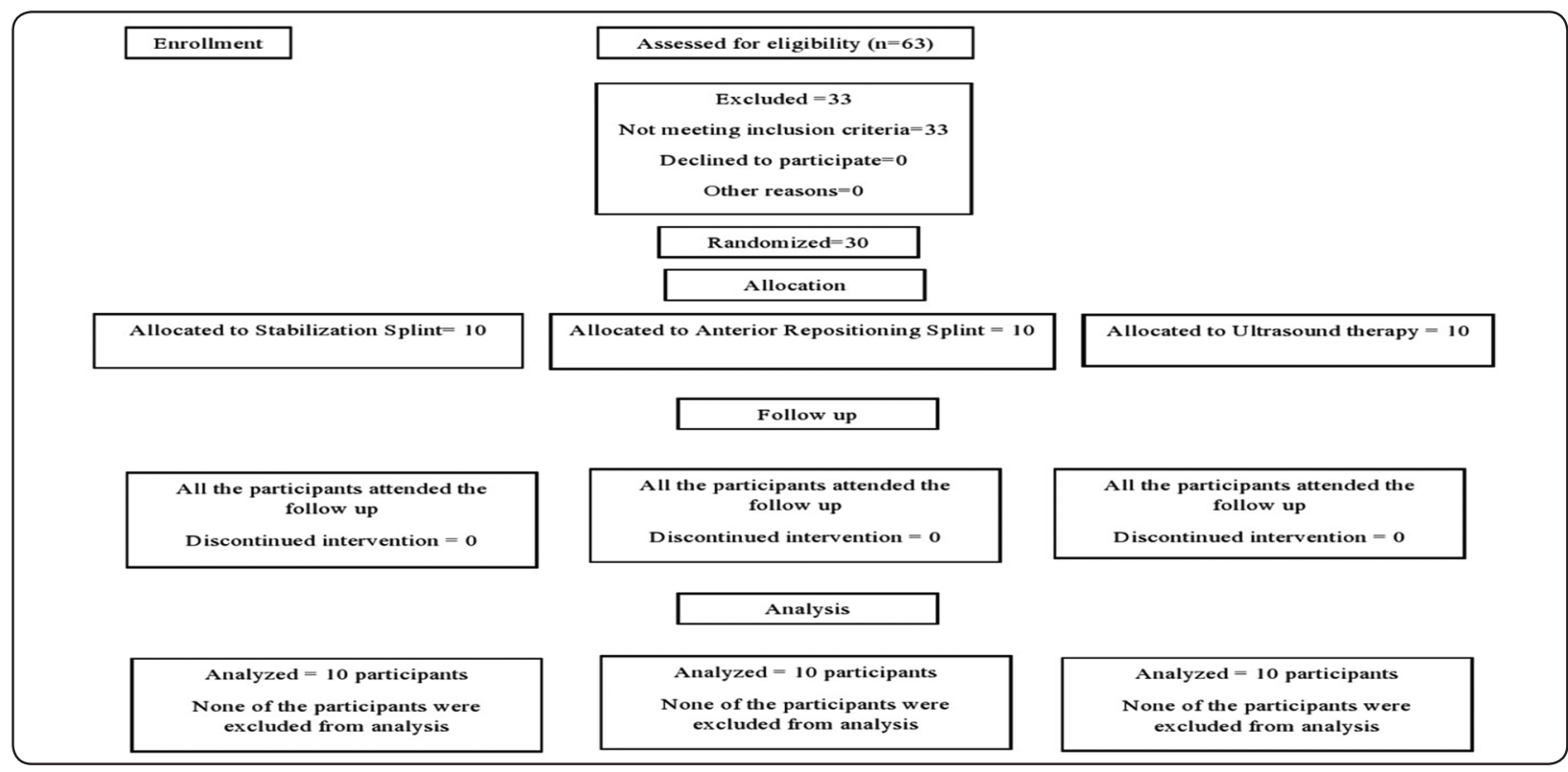

Fig. (5) Consort Flowchart

TABLE (1) Comparison of Visual Analogue Score (VAS) between the three groups and over time within each group

\begin{tabular}{|c|c|c|c|c|c|c|c|}
\hline \multirow{2}{*}{ VAS } & \multicolumn{2}{|c|}{$\begin{array}{c}\text { Group I } \\
\text { Stabilization splint }\end{array}$} & $\begin{array}{c}\text { Group II } \\
\text { Anterior repositioning splint }\end{array}$ & \multicolumn{2}{c|}{$\begin{array}{c}\text { Group III } \\
\text { Ultrasound therapy }\end{array}$} \\
\cline { 2 - 9 } & Mean & SD & Mean & SD & Mean & SD & P-value \\
\hline Baseline & $5.9^{\mathrm{aA}}$ & 1.3 & $6^{\mathrm{aA}}$ & 1.5 & $6.1^{\mathrm{aA}}$ & 1.4 & 0.951 \\
\hline $\mathbf{1 ~ m}$ & $1.4^{\mathrm{bB}}$ & 0.5 & $1.3^{\mathrm{bB}}$ & 0.5 & $1.6^{\mathrm{bB}}$ & 0.4 & 0.360 \\
\hline $\mathbf{3 ~ m}$ & $1^{\mathrm{cC}}$ & 0.2 & $0.9^{\mathrm{cC}}$ & 0.2 & $1^{\mathrm{cC}}$ & 0.1 & 0.344 \\
\hline $\mathbf{6} \mathbf{~ m}$ & $0.5^{\mathrm{dD}}$ & 0.1 & $0.4^{\mathrm{dD}}$ & 0.3 & $0.5^{\mathrm{dD}}$ & 0.2 & 0.499 \\
\hline P-value & \multicolumn{3}{|c|}{$<0.001^{*}$} & \multicolumn{2}{|c|}{$<0.001^{*}$} & & \\
\hline
\end{tabular}

Means with different small letters in the same column indicates significant difference, means with different capital letters in the same row indicates significant difference *; significant $(p<0.05)$

TABLE (2) Comparison of Maximum Mouth Opening (MMO) between the three groups and over time within each group

\begin{tabular}{|c|c|c|c|c|c|c|c|}
\hline \multirow{2}{*}{ MMO } & \multicolumn{2}{|c|}{$\begin{array}{c}\text { Group I } \\
\text { Stabilization splint }\end{array}$} & \multicolumn{2}{c|}{$\begin{array}{c}\text { Group II } \\
\text { Anterior repositioning splint }\end{array}$} & \multicolumn{2}{c|}{$\begin{array}{c}\text { Group III } \\
\text { Ultrasound therapy }\end{array}$} \\
\cline { 2 - 9 } & Mean & SD & Mean & SD & Mean & SD & P-value \\
\hline Baseline & $36.4^{\mathrm{aA}}$ & 5.2 & $34.2^{\mathrm{aA}}$ & 4.4 & $35.5^{\mathrm{aA}}$ & 4.1 & 0.566 \\
\hline $\mathbf{1 ~ m}$ & $41.4^{\mathrm{bB}}$ & 1.9 & $42.8^{\mathrm{bB}}$ & 2.1 & $35.9^{\mathrm{aC}}$ & 2.6 & $<0.001^{*}$ \\
\hline $\mathbf{3 ~ m}$ & $45.1^{\mathrm{cC}}$ & 1.6 & $46.9^{\mathrm{cC}}$ & 1.7 & $36.1^{\mathrm{aD}}$ & 1.3 & $<0.001^{*}$ \\
\hline $\mathbf{6} \mathrm{m}$ & $49.2^{\mathrm{dD}}$ & 2.1 & $50.8^{\mathrm{dD}}$ & 1.9 & $37.9^{\mathrm{aC}}$ & 2.8 & $<0.001^{*}$ \\
\hline P-value & \multicolumn{2}{|c|}{$<0.001^{*}$} & \multicolumn{2}{|c|}{0.269} & & \\
\hline
\end{tabular}

Means with different small letters in the same column indicates significant difference, means with different capital letters in the same row indicates significant difference *; significant $(p<0.05)$ 


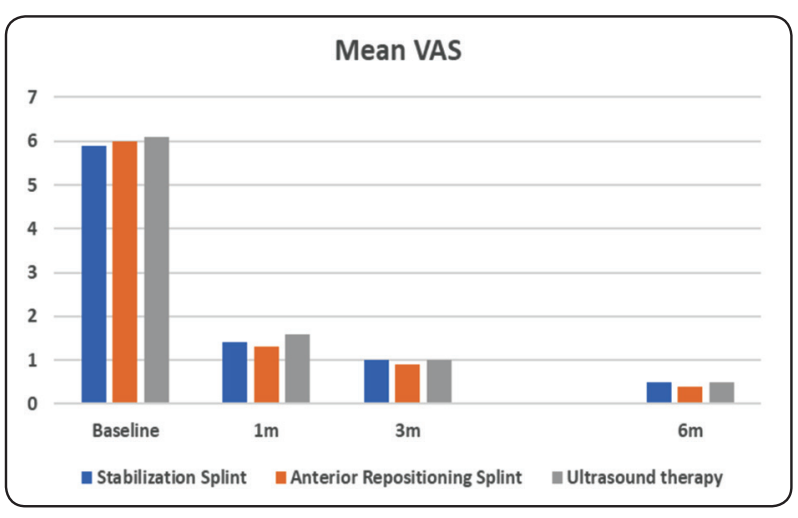

Fig. (6) A Bar Chart comparing the mean of Visual Analogue Score (VAS) of the study groups throughout different follow-up periods

\section{Clicking}

Although, ARS showed the best results regarding clicking as shown in Table $\mathbf{3}$ and $\mathbf{f i g}(\mathbf{8})$ yet, a non-significant difference was found between the study groups at 1 and $3 \mathrm{~m}$ with $\mathrm{P}=(0.535,0.142)$ respectively. A significant difference was revealed between the three groups at $6 \mathrm{~m}$ with $\mathrm{P}=0.034$.

By the end of the follow-up period, statistical improvement in clicking was present in SS group and ARS group with $\mathrm{P}=0.023$ and 0.010

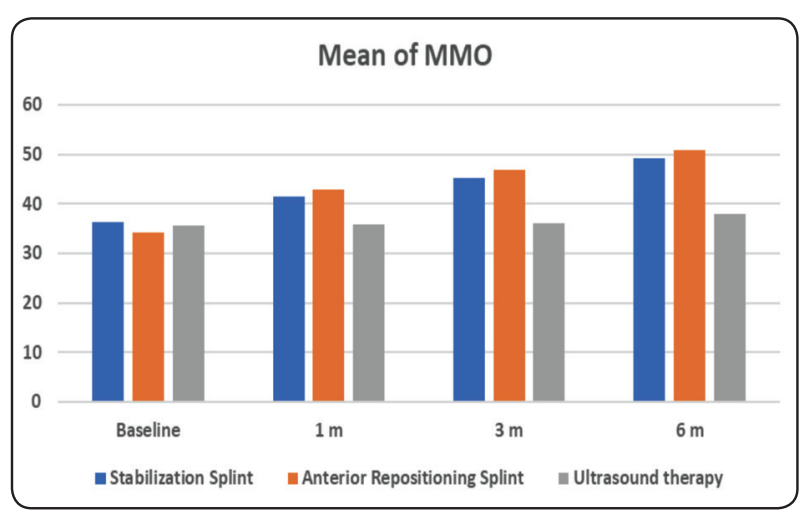

Fig. (7) A Bar Chart comparing mean of Maximum Mouth Opening (MMO) of the study groups throughout different follow-up periods

respectively. Most patients in the US group still had clicking sound without statistical improvement in clicking throughout the follow-up period $\mathrm{P}=0.782$. Comparison between each two groups showed a non-statistically significant difference at 1 and $3 \mathrm{~m}$. At $6 \mathrm{~m}$ a non-statistically significant difference was found between SS and ARS groups. Whereas, a statistically significant improvement was detected in SS and ARS when compared to US group.

TABLE (3) Comparison of clicking between the three groups and over time within each group

\begin{tabular}{|c|c|c|c|c|}
\hline Clicking & $\begin{array}{c}\text { Group I } \\
\text { Stabilization splint }\end{array}$ & $\begin{array}{c}\text { Group II } \\
\text { Anterior repositioning splint }\end{array}$ & $\begin{array}{c}\text { Group III } \\
\text { Ultrasound therapy }\end{array}$ & P-value \\
\hline Baseline & $10 / 10$ & $10 / 10$ & $10 / 10$ & - \\
\hline $1 \mathrm{~m}$ & $8 / 10^{\mathrm{aA}}$ & $7 / 10^{\mathrm{aA}}$ & $9 / 10^{\mathrm{aA}}$ & 0.535 \\
\hline $3 \mathrm{~m}$ & $6 / 10^{\mathrm{bB}}$ & $5 / 10^{\mathrm{bB}}$ & $9 / 10^{\mathrm{aB}}$ & 0.142 \\
\hline $6 \mathrm{~m}$ & $4 / 10^{\mathrm{cA}}$ & $3 / 10^{\mathrm{cA}}$ & $9 / 10^{\mathrm{aC}}$ & $0.034^{*}$ \\
\hline P-value & $0.023^{*}$ & $0.010^{*}$ & 0.782 & \\
\hline
\end{tabular}

The numbers in each group represents the presence of clicking. Numbers with different small letters in the same column indicates significant difference, numbers with different capital letters in the same row indicates significant difference *; significant $(p<0.05)$ 


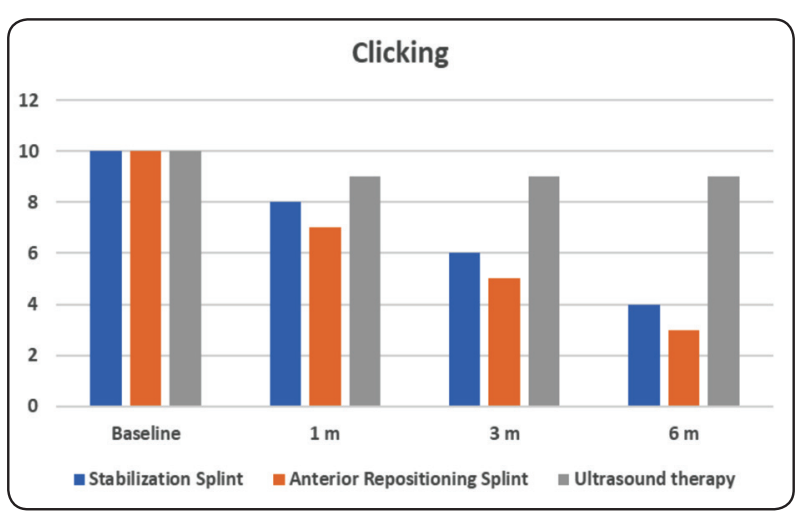

Fig. (8) A Bar Chart comparing the presence of clicking in the study groups throughout different follow-up periods

\section{DISCUSSION}

Occlusal splints and US therapy were chosen for treatment of ADDwR in the present study. Previous studies have shown their effectiveness in the management of signs and symptoms of ADDwR as they can help in alleviation of pain and are efficient in displaced disc recapture. ${ }^{22-27}$

Regarding pain the null hypothesis was accepted as there was no significant difference between the study groups in all the follow-up periods. This can be comparable to a previous study which compared self-care instructions, ARS and physiotherapy and found out that there was no significant difference between the three groups regarding pain after $4 \mathrm{~m} .{ }^{28}$ Other studies showed a non-significant difference between SS and ARS in reduction of muscle pain related to TMD. ${ }^{29,30}$

Improvement of pain after using occlusal splints can be attributed to the fact that the even thickness of the occlusal splint causes an increase of the vertical dimension. This in turn, results in relaxation of muscles during rest position and relief of pain. ${ }^{31}$ Moreover, occlusal decoupling can cause redirection of the established neuromuscular reflex mechanisms and reduces the biting force and the joint load. ${ }^{32,33}$ In addition, the new intraoral devices are believed to interfere with the effect of trigeminal neural circuits. ${ }^{34}$
There is a controversy about the recommended type of splint. As mentioned by a previous study; in management of TMD using ARS, the mandible can return back to its previous position after therapy when the splint use is discontinued and suggested the use of SS in internal TMJ disorders. ${ }^{10}$ On the other hand, other authors recommended the use of ARS as when the mandible is kept in an anterior position, the displaced disc would be recaptured into its normal position with the aid of direction of muscles pull which is anterior and medial.

In the present study, SS was found to be effective in decreasing the severity of pain. This is in similarity to a study comparing SS to a placebo splints in patients with TMD. TMJ pain was evaluated using VAS for a period of 10 weeks. The severity of pain decreased significantly in the SS group. ${ }^{35}$

Additionally, ARS has shown successful results in reduction of pain and success in recapturing of anteriorly displaced discs in cases of ADDwR. Whereas, the change in the disc morphology and the existence of inflammatory process causes failure in cases of ADDWoR. ${ }^{36}$ Another study revealed that the ARS was effective against pain and clicking and was significantly higher than the bite plane in patients with ADDwR. ${ }^{37}$

Ultrasound waves caused early improvement in pain which can be due to several factors including acoustic vibrations which causes the movement of fluids, macromolecules and cell membrane. Additionally, alteration of cell metabolism and growth due to mechanical stimulation that eventually changes the biological and physical properties of the cells.$^{38}$

Comparing SS and ARS, a non-significant difference was detected in the treatment efficiency of both groups and they showed a decrease in pain, clicking sound and increase in MMO. This is in similarity to a study comparing both types of splints and found that they had positive effects on TMD. ${ }^{39}$ 
There is a significant difference between the three groups in MMO and clicking, thus the null hypothesis was rejected. Nevertheless, in our study; when SS and ARS were compared separately; improvement in the $\mathrm{MMO}$ and clicking was observed by the end of the follow-up period, where the mean of MMO was $49.2 \pm 2.1 \mathrm{~mm}$ and $50.8 \pm 1.9$ in SS and ARS groups respectively.

Improvement in $\mathrm{MMO}$ can be due to decrease in joint pain possibly accompanied with the recovery of co-contraction of secondary muscles. A slight improvement in MMO was recorded in US group which was $37.9 \pm 2.8$. This can be comparable to a study comparing self-care, ARS and physiotherapy and showed slight improvement in MMO in the group treated with physiotherapy. ${ }^{28}$

TMD patients frequently complain from clicking sounds despite the fact that asymptomatic subjects can complain from clicking and no intervention is needed. ${ }^{36,40}$ Joint sound is considered to be due to problems in the ligaments, change in the disc anatomy, joint fibers and change in the position of the disc. ARS was found to manage successfully the clicking sound ${ }^{41,42}$

Statistical improvement in clicking was present in 4 patients in SS group and 3 patients in ARS group. 9 patients in the US group still had clicking sound without statistical improvement in clicking throughout the follow-up period.

Resolution of clicking sound can be due to alteration in the morphology in the disc itself in the posterior area, which consequently could remove the physical barrier for the translating condyle, and hence decreasing the sound. ${ }^{43}$

The limitations of the present study include small sample size. Future RCTs with larger sample size would result in more reliable results. Additionally, longer follow-up period was needed to detect if the symptoms will return in the long-term following treatment.

\section{CONCLUSION}

The use of occlusal splints in the management of painful ADDwR is a successful mode of treatment and helps in decreasing pain, improving MMO and clicking. Using US therapy could be beneficial in decreasing pain but showed no improvement in MMO and clicking and is better to be used in combination with other treatment modalities.

\section{REFERENCES}

1. Garrigós M, Elizagaray-García I, Domínguez AA, Delcastillo JL, Gil-Martinez A. Temporomandibular disorders :improving outcomes using a multidisciplinary approach. J MultidiscipHealthc. 2019;12:733-747

2. Conti PCR, Da Mota Correa AS, Lauris JRP, StuginskiBarbarosa J. Management of painful temporomandibular joint clicking with different intraoral devices and counseling : a controlled study. J Appl Oral Sci. 2015;23:529-535.

3. E. Schiffman, R. Ohrbach, E. Truelove et al., "Diagnostic criteria for temporomandibular disorders (DC/TMD) for clinical and research applications: recommendations of the International RDC/TMD Consortium Network and Orofacial Pain Special Interest Group. Journal of Oral and Facial Pain and Headache.2014 ; 28, 6-27.

4. Okeson JP. Joint Intracapsular Disorders: Diagnostic and Nonsurgical Management Considerations. Dent Clin North Am. 2007;51:85-103.

5. Tjang SA, Tanti I. Anterior repositioning splint treatment consideration for cases of disc displacement with reduction. Indonesian Journal of Prosthodontics. 2020 Jun 12;1:4-11.

6. Pihut M, Gorecka M, Ceranowicz P, Wieckiewicz M. The efficiency of anterior repositioning splints in the management of pain related to temporomandibular joint disc displacement with reduction. Pain Research and Management. 2018 Feb 21;2018.

7. Alqutaibi AY, Aboalrejal AN. Types of Occlusal Splint in Management of Temporomandibular. J Arthritis. 2015; 4:176.

8. Seifeldin SA, Elhayes KA. Soft versus hard occlusal splint therapy in the management of temporomandibular disorders (TMDs). Saudi Dent J 2015;27:208-14.

9. Stiesch-Scholz M, Kempert S, Wolter H, Tschernitschek $\mathrm{H}$ : Comparitave prospective study on splint therapy of anterior disc displacement without reduction. J Oral Rehabil 2005, 32:474-479. 
10. Lundh H, Westesson PL, Kopp S, Tillström B. Anterior repositioning splint in the treatment of temporomandibular joints with reciprocal clicking: comparison with a flat occlusal splint and an untreated control group. Oral Surgery, Oral Medicine, Oral Pathology. 1985 ;60:131-6.

11. Di Fabio RP. Physical therapy for patients with TMD: a descriptive study of treatment, disability, and health status. J Orofac Pain .1998;12:124-35.

12. Gray RJ, Quayle AA, Hall CA, et al. Physiotherapy in the treatment of temporomandibular joint disorders: a comparative study of four treatment methods. Br Dent $\mathrm{J}$ .1994; 176:257-61

13. Yadav S, Karani JT. The essentials of occlusal splint therapy. Int J Prosthet Dent. $2011 ; 2: 12-21$.

14. Maloney F, Howard JA. Internal derangements of the temporomandibular joint. III. Anterior repositioning splint therapy. Australian Dental Journal.1986; 31:30-39.

15. Davies SJ, Gray RJ. The pattern of splint usage in the management of two common temporomandibular disorders. Part I:The anterior repositioning splint in the treatment of disc displacement with reduction. British Dental Journal.1997; 183:199-203.

16. Gil-Martinez A, Paris-Alemany A, Lopez-de-Uralde-Villanueva I, La Touche R .Management of pain in patients with temporomandibular disorder (TMD): challenges and solutions. J Pain Res.2018 ;11: 571-587.

17. Linde C, Isacsson G, Jonsson BG. Outcome of 6-week treatment with transcutaneous electric nerve stimulation compared with splint on symptomatic temporomandibular joint disk displacement without reduction. Acta Odontol Scand .1995;53:92-8.

18. Ficnar T, Middelberg C, Rademacher B, et al. Evaluation of the effectiveness of a semi-finished occlusal appliance-a randomized, controlled clinical trial. Head Face Med. 2013;9:5

19. Glaros AG, Kim-Weroha N, Lausten L, et al. Comparison of habit reversal and a behaviorally-modified dental treatment for temporomandibular disorders: a pilot investigation. Appl Psychophysiol Biofeedback 2007;32:149-54.

20. Michelotti A, Iodice G, Vollaro S, et al. Evaluation of the short-term effectiveness of education versus an occlusal splint for the treatment of myofascial pain of the jaw muscles. J Am Dent Assoc. 2012;143:47-53.

21. Look JO, Schiffman EL, Truelove EL, Ahmad M .Reliability and validity of Axis I of the Research Diagnostic Criteria forTemporomandibular Disorders (RDC/TMD) with proposed revisions. J Oral Rehabil .2010.3;7: 744-759.
22. Al-Baghdadi M, Durham J, Araujo-Soares V, et al. TMJ disc displacement without reduction management: asystematic review. J Dent Res. 2014;93:37S-51S.

23. Conti PCR, de Alencar EN, da Mota Correa AS, et al. Behavioural changes and occlusal splints are effective in the management of masticatory myofascial pain: a short term evaluation.J Oral Rehabil.2012;39:754-60.

24. Cleland J, Palmer J. Effectiveness of manual physical therapy, therapeutic exercise, and patient education onbilateral disc displacement without reduction of thetemporomandibular joint: a single-case design. J Orthop Sports Phys Ther .2004;34:535-48.

25. Kuttila M, Bell YL, Savolainen-Niemi E, et al. Efficiency of occlusal appliance therapy in secondary otalgia and temporomandibular disorders. Acta Odontol Scand. 2002;60:248-54

26. E. L. Schiffman, A. M. Velly, J. O. Look et al., "Effects of four treatment strategies for temporomandibular joint closed lock," International Journal of Oral and Maxillofacial Surgery .2014; 43:217-26.

27. Haketa T, Kino K, Sugisaki M, Takaoka M, Ohta T. Randomized clinical trial of treatment for TMJ disc displacement. Journal of dental research. 2010 ;89:1259-63.

28. Majid IA, Mubeen FK.Physiotherapy and Anterior Repositioning Splint in the Treatment of Disk Displacement with Reduction - A Randomized Controlled Trial, J Evolution Med Dent Sci. 2020; 9 .

29. Conti PCR, Miranda JES , Conti AF, Pegoraro LF, Araújo CRP. Partial Time Use of Anterior Repositioning Splints In The Management of TMJ Pain And Dysfunction: A OneYear Controlled Study. J Appl Oral Sci. 2005;13: $345-50$

30. Devi J, Verma M, Gupta R (2017) Assessment of treatment response to splint therapy and evaluation of TMJ function using joint vibration analysis in patients exhibiting TMJ disc displacement with reduction: A clinical study. Indian J Dent Res 28: 33-43

31. Amin A, Meshramkar R and Lekha K. Comparative evaluation of clinical performance of different kind of occlusal splint in management of myofascial pain. The $\mathrm{J}$ of Indian Prosthodontic Society. 2016; 16: 176-181

32. Boero RP: The physiology of splint therapy: a literature review. Angle Orthod 1989; $59: 165-80$

33. Schmitter M, Zabran M, Phu Duc JM, Henschel V and Rammelsberg P: Conservative therapy in patient with anterior disc displacement without reduction using 
2 common splints: randomized clinical trail. J Oral Maxillofag Surg 2005; 63:1295-303.

34. Klasser GD, Greene CS. Oral appliances in the management of temporomandibular disorders. Oral Surg Oral Med Oral Pathol Oral Radiol Endod .2009;107:212-23.

35. Ekberg E, Vallon D and Nilner : Occlusal appliance therapy in the patient temporomandibular disorders. A doubled controlled study in a short term prespective. Acata odontol scand. 1996; 56:122.

36. Kurita H, Ohtsuka A, Kurashina K, Kopp S. A study of factors for successful splint capture of anteriorly displaced temporomandibular joint disc with disc repositioning appliance. J Oral Rehabil. 28:651-7-2001.

37. Santacatterina A, Paoli M, Peretta R, Bambace A, Beltrame A .A comparison between horizontal splint and repositioning splint in the treatment of 'disc dislocation with reduction'. Literature meta-analysis. J Oral Rehabil. 1998; 25: 81-88.
38. ter Haar G. Therapeutic applications of ultrasound. Prog Biophys Mol Biol 2007;93:111-29.

39. Kerem K, Kurtulus ER, Ikbal L. Comparison of the Efficacy of Two Different Types of Splint Used in Patients with TemporomandibularJoint Disorders. Biomed J Sci Tech Res. 2018;6:5217-24.

40. Okeson JP. Orofacial pain. Guidelines for assessment, diagnosis and management. Chicago: Quintessence; 1995.

41. Boever JA. Functional disturbances of the Temporomandibular Joints. Oral Sci Rev. 1:100-17- 1973.

42. Sfondrini G, Regianni C, Gandini P, Bovenzi R, Pellegrino MA. Adaptations of masticatory muscles to a hyperpropulsiveappliance in the rat. Amer J OrthodDentofacOrthop.10:612-7-1996.

43. Conti PC, Santos CN, Kogawa EM, Castro Ferreira Conti AC, Araujo CR. The treatment of painful temporomandibular joint clicking with oral splints: a randomized clinical trial. J Am Dent Assoc. 2006;137:1108-14 